\title{
Structural relationship of leadership qualities with worker's issues for Saudi Arabia's construction industry
}

\author{
Ismail Abdul Rahman ${ }^{1}$, and Nashwan Al-Emad ${ }^{1, *}$ \\ ${ }^{1}$ Department of Building and Construction Engineering, Faculty of Civil and Environmental \\ Engineering, Universiti Tun Hussein Onn Malaysia, 86400 Parit Raja, Batu Pahat, Johor, Malaysia.
}

\begin{abstract}
One of the important factors for construction project success is managing the workers. It requires good leadership qualities in handling the workers' issues. This paper presents a study on associating good leadership qualities with the workers issues of Saudi Arabia's construction industry. The study was conducted within Makkah development region where all the construction workers are foreigners. A questionnaire survey involved 203 construction leaders who were asked to rate the degree of importance of each the identified leadership qualities in handling several construction workers issues. Collected data from this survey was used to develop PLSSEM model which relates structural relationship of leadership qualities with the worker issues. Validation of the model shows that it is fit with Goodness of Fit (GoF) value of 0.30 . The validated model indicates that problem solving group of qualities is the most dominant in handling workers issues. These findings are helpful for Saudi Arabia's construction practitioners in handling workers issues effectively and thus ensure completion of construction projects timely.
\end{abstract}

\section{Introduction}

Construction's leadership is important factor in ensuring the success of construction projects [1,2]. It considered a crucial aspect in all fields of human endeavor but more essential for the construction industry which requires a quality construction project management team [3]. In nature, construction industry is unique, fragmented and resources driven, hence issues faced by construction industry are tremendous in numbers such as delay, cost overrun, quality, productivity, workmanship, safety, waste and human related issues. These issues engulfed construction industry in every country including Saudi Arabia where the Saudi's construction industry faces several impediments and challenges to be completed successfully. Recently, Saudi's construction industry witnessed a noticeable regression due to several reasons including drop of oil price and intervention military in Yemen which have exposed the country to growing risks, lowering scores in this industry [4]. Nevertheless of construction boom in the country in the last decades, the construction

\footnotetext{
* Corresponding author: df080116@gmail.com
} 
industry of Saudi Arabia is facing chronic problems such as delay, cost overrun $[5,6]$ and poor safety [7].

Construction workers are one of the most important factors for construction project success because constructions tasks mainly implemented by this group regardless of their skilled or unskilled. In Saudi Arabia's construction industry, most of the construction workers are foreigners from several countries with different knowledge, skills and cultures. These workers face many problems in their daily life, problems not only related to construction demanding tasks but also related to social, cultural and climate adoption. Restrictions to non-Muslim skilled workers, limited visa quota, being away from family, delay in salary payment, cheating of workers skill's status, safety issues, communication barriers and living conditions among the important issues engulfing workers in Makkah's construction industry [8]. Besides that Almannaee, [9] and Andrieu et al., [10] have identified problems faced by workers in Saudi Arabia including shortage of skilled workforce, poor living condition, low wages, delaying in wages payment, poor living condition, safety issues. These problems have adverse impacts to construction project performance which requires serious attention by construction leaders to handle them.

Construction industry requires a professional who possesses quality management and leadership skills to steer projects successfully [11]. Although experience and technical background are important in engineering and construction field, but the critical part should be required by construction leader is the leadership and managerial qualities [1]. According to Benator \& Thumann [12], leadership and management expertise can help the construction leader to achieve the project objectives timely. Moreover, good leadership qualities of construction leader are essential component for steering construction project successfully. Thus to be outstanding leaders, they should possess good leadership attributes such as problem solver, communicator and motivator in their organizations [13]. Hence, this paper has uncovered 56 leadership qualities from previous researchers. These leadership qualities are then classified into 6 groups which were used as latent variables which comprises of independent variables of leadership qualities in developing PLS-SEM structural model. Besides that, this study has identified 21 issues engulfed construction workers from past literature review. Worker issues group was used as dependant variable in developing structural relationships model to associate appropriate leadership qualities with worker issues.

\section{Methodology}

Quantitative data was collected using questionnaire survey to gauge the level of importance of each leadership quality in handling several workers issues. The important items in the questionnaire are list of leadership quality and also workers issues which were extracted from on literature review work. Prior to data collection, the questionnaire survey form was evaluated through pilot survey to check the relevance and workability of the survey questions to the construction industry of Makkah city. The pilot survey involved 31 experts who have more than 10 years of working experience in Saudi construction industry. The feedback of pilot survey was then used for improving the contents of the questionnaire form. The final form of the questionnaire was used for data collection where the forms were distributed to the targeted construction leaders from contractor's organizations in Makkah city through site visit and managed to secure 203 valid responses. Respondents were requested to indicate the level of importance based on 5-points Likert's scale on each of the identified 56 leadership qualities in resolving the identified workers' issues. 


\subsection{Model development}

A model is developed using PLS-SEM method which relate leadership qualities with workers issues for the construction industry of Makkah city. This method uses Partial Least Square (PLS) technique which is a second generation of multivariate statistical analysis that simultaneously evaluates multiple variables[14]. Before a model can be developed in SmartPLS software, a theoretical/hypothetical model has to be formulated for identifying the relationships between the constructs. To identify the conceptual path model, it must begin with fundamental explications about the model which usually build on existing research knowledge [15]. In this content, the theoretical model is based on 6 groups of leadership qualities (independent variables). These 6 groups are converged to one dependent variable that is "workers' issues". Based on these groups, the theoretical model is hypothesized as figure 1 .

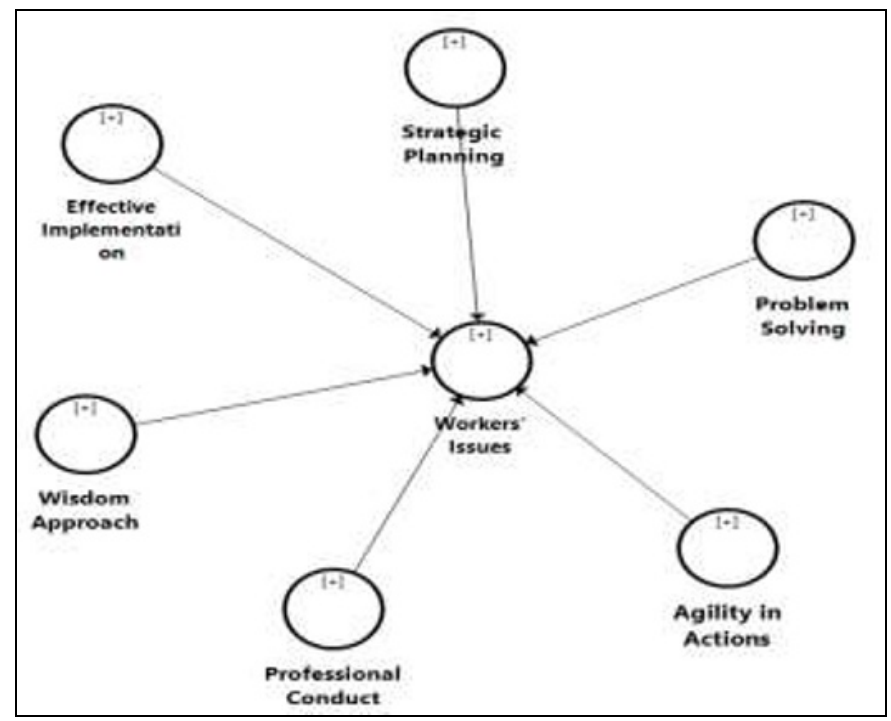

Fig. 1. Theoretical Model of the Study.

This theoretical model of figure 1 is applied in SmartPLS 3.0 software to develop a relationship of leadership qualities with worker issues. The model was developed based on 56 leadership qualities (items) assigned to 6 groups (known as independent variables) namely as Strategic Planning (SP) with 8 items, Effective Implementation (EI) with 11 items, Wisdom Approach (WA) with 14 items, Professional Conduct (PC) with 6 items, Problem Solving (PS) with 7 items and Agility in Actions (AA) with 10 items. These 6 groups are converged to one dependent variable named as worker issues consisted of 21 items (issues). Raw data for model development were derived from the questionnaire survey which involved 203 respondents who are construction leaders working in Makkah's construction industry. Number of raw data used to develop a structural relationship model between leadership qualities and workers' issues is 15631 which include 21 issues plus 56 qualities multiplied by 203 respondents. These data are recorded in sav format of excel software and then converted into the .csv format by using (save As) function in the software. Once the data is converted, the following step is to create a new project sheet in SmartPLS and then import the data to the project worksheet. After importing the data to SmartPLS software the next steps are to draw the path model according to the hypothetical model, assigned name of constructs, connecting the independent variables with dependent variable and assigning the items to the respective construct and then the model is ready for 
modelling processes. Modelling process is commenced with PLS algorithm in the software with the number of iterations set at 300 [16]. Throughout the process, some of the items found unreliable having outer loadings below 0.5 which represents the correlations of the items with their respective latent variables. According to Hulland [17], items with loading of 0.7 or more are considered significant items and suggested that items with loadings of less than 0.4 should be dropped. However, item with loading between 0.4 to 0.7 be reviewed and may be dropped if they do not increase value to composite reliability [18]. During the modelling process, several weak items were generated and eliminated at each iterative process as suggested by Aibinu et al. [19]and Rahman \& Nagapan, [20] in order to obtain a fit PLS model. 12 iterative processes were carried out before reaching reliability of all the items resulted in deleting 26 weak items (15 qualities and 11 issues) and left 51 significant items (41 qualities and 10 issues) which are reliable for the final graphical representation. The final structural relationships model of leadership qualities with workers' issues for Saudi Arabia's construction industry is portrayed as figure 2.

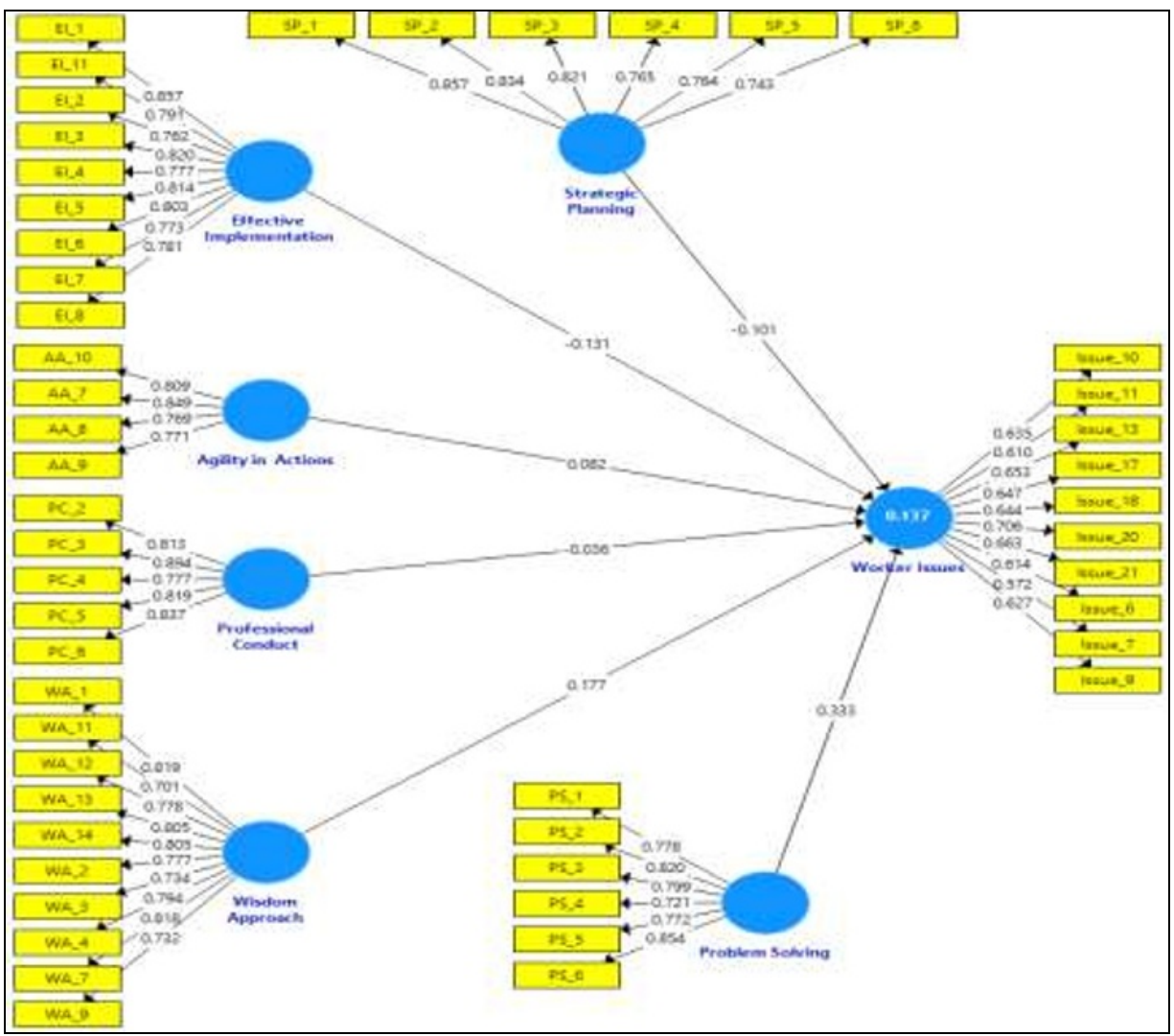

Fig. 2. The Final Structural Relationship Model of the Study.

The required assessments of the developed PLS-SEM path model of structural relationship between leadership qualities and worker issues for Makkah's construction industry (figure 2) were carried out which involved assessing measurement model, assessing structural model and overall assessment as discussed in the following sections. 


\section{Results and Analysis}

Data analysis is carried out using SmartPLS software to relate good leadership qualities with workers issues for Saudi's construction industry. In order to ensure the results of each leadership quality has impact towards workers issues, the model needs to be assessed. The assessments process involves 3 essential steps that are assessing measurement mode, assessing structural model and overall assessment on the model. These assessments are elaborated in more details as in the following subsections.

\subsection{Assessing measurement model}

Assessment of measurement model (outer model) is to check internal consistency of the model whether relationships between independent and manifest/items variables are adequate [14]. According to Hair et al. [18], assessment of the measurement model includes estimating the composite reliability, average variance extracted (AVE), Cronbach's alpha, reliability of individual indicators and discriminant validity. Required threshold values for the parameters are Average Variance Extracted (AVE) $\geq 0.5$. However, AVE equal to 0.4 can be accepted if the composite reliability is higher than 0.6 for the particular construct [21]. For Composite Reliability (CR), it should be $\geq 0.7$ and Cronbach's alpha should be $\geq$ 0.7 [18]. For individual item reliability, each manifest is considered significant if its loading value is more than 0.5 [18]. Results of individual items reliability and convergent validity for independent variables (leadership qualities groups) are presented as in table 1 . 
Table 1. Measurements Model Results for Independent Variables.

\begin{tabular}{|c|c|c|c|c|c|c|}
\hline Items & Description & Loading & Construct & Alpha & $\mathbf{C R}$ & AVE \\
\hline AA_10 & Alert with project details & 0.809 & \multirow{4}{*}{$\begin{array}{l}\text { Agility in } \\
\text { Actions }\end{array}$} & \multirow{4}{*}{0.814} & \multirow{4}{*}{0.877} & \multirow{4}{*}{0.640} \\
\hline AA_7 & $\begin{array}{l}\text { Very focused in achieving } \\
\text { tasks }\end{array}$ & 0.849 & & & & \\
\hline AA_8 & Prioritizing tasks & 0.769 & & & & \\
\hline AA_9 & $\begin{array}{l}\text { Alert with contractual } \\
\text { compliance }\end{array}$ & 0.771 & & & & \\
\hline EI_1 & Effective management & 0.857 & \multirow{9}{*}{$\begin{array}{c}\text { Effective } \\
\text { Implementation }\end{array}$} & \multirow{9}{*}{0.930} & \multirow{9}{*}{0.940} & \multirow{9}{*}{0.637} \\
\hline EI_11 & Develop good team members & 0.791 & & & & \\
\hline EI_2 & $\begin{array}{l}\text { Evaluating targets } \\
\text { continuously }\end{array}$ & 0.762 & & & & \\
\hline EI 3 & Effective time management & 0.820 & & & & \\
\hline EI_4 & $\begin{array}{l}\text { Continuous quality } \\
\text { improvement }\end{array}$ & 0.777 & & & & \\
\hline EI_5 & $\begin{array}{l}\text { Handling situation } \\
\text { confidently }\end{array}$ & 0.814 & & & & \\
\hline EI_6 & $\begin{array}{l}\text { Effective resources } \\
\text { management }\end{array}$ & 0.803 & & & & \\
\hline EI_7 & Having Sufficient experience & 0.773 & & & & \\
\hline EI_8 & Effective negotiation capacity & 0.781 & & & & \\
\hline PS $\_1$ & Decision making capacity & 0.778 & \multirow{6}{*}{$\begin{array}{l}\text { Problem } \\
\text { Solving }\end{array}$} & \multirow{6}{*}{0.883} & \multirow{6}{*}{0.910} & \multirow{6}{*}{0.627} \\
\hline PS_2 & Problem solving capacity & 0.820 & & & & \\
\hline PS_3 & $\begin{array}{l}\text { Decisive in resolving } \\
\text { problems }\end{array}$ & 0.799 & & & & \\
\hline PS_4 & $\begin{array}{l}\text { Develop trust with } \\
\text { stakeholders }\end{array}$ & 0.721 & & & & \\
\hline PS_5 & Resolving conflict & 0.772 & & & & \\
\hline PS_6 & $\begin{array}{l}\text { Proactive in avoiding } \\
\text { problems }\end{array}$ & 0.854 & & & & \\
\hline PC_ 2 & Integrity & 0.813 & \multirow{5}{*}{$\begin{array}{l}\text { Professional } \\
\text { Conduct }\end{array}$} & \multirow{5}{*}{0.886} & \multirow{5}{*}{0.916} & \multirow{5}{*}{0.687} \\
\hline $\mathrm{PC} 33$ & Honest and trustworthy & 0.894 & & & & \\
\hline PC_ 4 & Ethical behavior & 0.777 & & & & \\
\hline PC_5 & Perform work sincerely & 0.819 & & & & \\
\hline PC_6 & $\begin{array}{l}\text { Willingness to take } \\
\text { responsibility }\end{array}$ & 0.837 & & & & \\
\hline SP_1 & Effective planning & 0.857 & \multirow{6}{*}{$\begin{array}{l}\text { Strategic } \\
\text { Planning }\end{array}$} & \multirow{6}{*}{0.889} & \multirow{6}{*}{0.913} & \multirow{6}{*}{0.638} \\
\hline SP_2 & setting Goal & 0.834 & & & & \\
\hline SP_3 & Creating strategies & 0.821 & & & & \\
\hline SP 4 & Assessing risks & 0.765 & & & & \\
\hline SP 5 & Clear mission \& vision & 0.764 & & & & \\
\hline SP_8 & Success oriented & 0.743 & & & & \\
\hline WA_1 & Respectful with workers & 0.819 & \multirow{10}{*}{$\begin{array}{l}\text { Wisdom } \\
\text { Approach }\end{array}$} & \multirow{10}{*}{0.928} & \multirow{10}{*}{0.938} & \multirow{10}{*}{0.604} \\
\hline WA_11 & Influencing workers & 0.701 & & & & \\
\hline WA_12 & Empathy with workers & 0.778 & & & & \\
\hline WA_13 & Effective communication & 0.805 & & & & \\
\hline WA_14 & $\begin{array}{l}\text { Fair treatment regardless } \\
\text { nationalities }\end{array}$ & 0.805 & & & & \\
\hline WA_2 & Sincere with workers & 0.777 & & & & \\
\hline WA 3 & Persuasiveness capacity & 0.734 & & & & \\
\hline WA 4 & Good listener & 0.794 & & & & \\
\hline WA_7 & Reliable with workers & 0.818 & & & & \\
\hline WA 9 & Good motivator & 0.732 & & & & \\
\hline
\end{tabular}


Generated results of independent variables for the measurement model as in table 1, indicates that all values of composite reliability, average variance extracted (AVE), Cronbach's alpha and reliability of individual indicators are above the cut-off values. Besides that, the results measurement model (individual items reliability and convergent validity) for the dependent variable (worker issues) are shown as table 2.

Table 2.Measurements Model Results for Dependent Variables.

\begin{tabular}{|c|c|c|c|c|c|c|}
\hline Items & Description & Loading & Construct & Alpha & CR & AVE \\
\hline Issue_10 & Insecurity of job & 0.635 & \multirow{10}{*}{$\begin{array}{l}\text { Worker } \\
\text { Issues }\end{array}$} & \multirow{10}{*}{0.840} & \multirow{10}{*}{0.873} & \multirow{10}{*}{0.407} \\
\hline Issue_11 & Low salaries & 0.610 & & & & \\
\hline Issue_13 & $\begin{array}{l}\text { Discrimination in wages } \\
\text { distribution }\end{array}$ & 0.653 & & & & \\
\hline Issue_17 & $\begin{array}{l}\text { Lack of incentives affecting } \\
\text { targeted performance }\end{array}$ & 0.647 & & & & \\
\hline Issue_18 & $\begin{array}{l}\text { Crowded accessible area to } \\
\text { the project }\end{array}$ & 0.644 & & & & \\
\hline Issue_20 & Absence of overtime & 0.706 & & & & \\
\hline Issue_21 & $\begin{array}{l}\text { Disruption of work due to } \\
\text { Strike }\end{array}$ & 0.663 & & & & \\
\hline Issue_6 & Lack of orientation programs & 0.614 & & & & \\
\hline Issue_7 & $\begin{array}{l}\text { Restriction in bringing } \\
\text { worker's family }\end{array}$ & 0.572 & & & & \\
\hline Issue_9 & Delay in payment & 0.627 & & & & \\
\hline
\end{tabular}

Results of dependent variable shown in table 2 are within the acceptable threshold values as suggested by $[18,21]$. To assess discriminant validity; two essential requirements should be met. These include the outer loading of each indicator should be higher than its loadings on other constructs, and according to Fornell-Larcker criteria, the square root of AVE of each construct should be higher than its highest correlation with any other construct [16,21]. Generated values of the model found that the outer loading of each item/manifest variable is higher in their relative independent variable than other independent variables. And also the correlation values of the independent variables of the model are higher than non-diagonal values. This indicates that the developed model has achieved its discriminant validity assessment.

\subsection{Assessing structural model}

After the measurement model has achieved its threshold values, the following step is to assess the structural model. This involves examining relationship between dependent variable with independent variables. It is carried out by checking the strength of impact path $(\beta)$ of independent variable to the dependent variable and also the explanatory power $\left(\mathrm{R}^{2}\right)$. A structural path can be considered acceptable if the $\beta$-value is above 0.1 [18]. According to Aibinu and Al-Lawati [22], the higher $\beta$-value shows the stronger impact of a predictor independent variable on the dependent variable. Another criterion to assess structural model is explanatory power. It is to examine the overall ability of the model in representing the impact of independent variables toward the dependent variable [14]. The indicator used to describe the explanatory power is the model's coefficient of determination which is $\mathrm{R}^{2}$ value [18]. According to Cohen [23], a model can be assessed as substantial if $\mathrm{R}^{2}=0.26$, moderate if $\mathrm{R}^{2}=0.13$ and weak if $\mathrm{R}^{2}=0.02$. Results of structural model assessment are as presented in figure 3 . The $\mathrm{R}^{2}$ value is 0.137 which means that the 
developed model has moderate explaining power in representing the impact of the groups of leadership qualities in handling workers' issues.

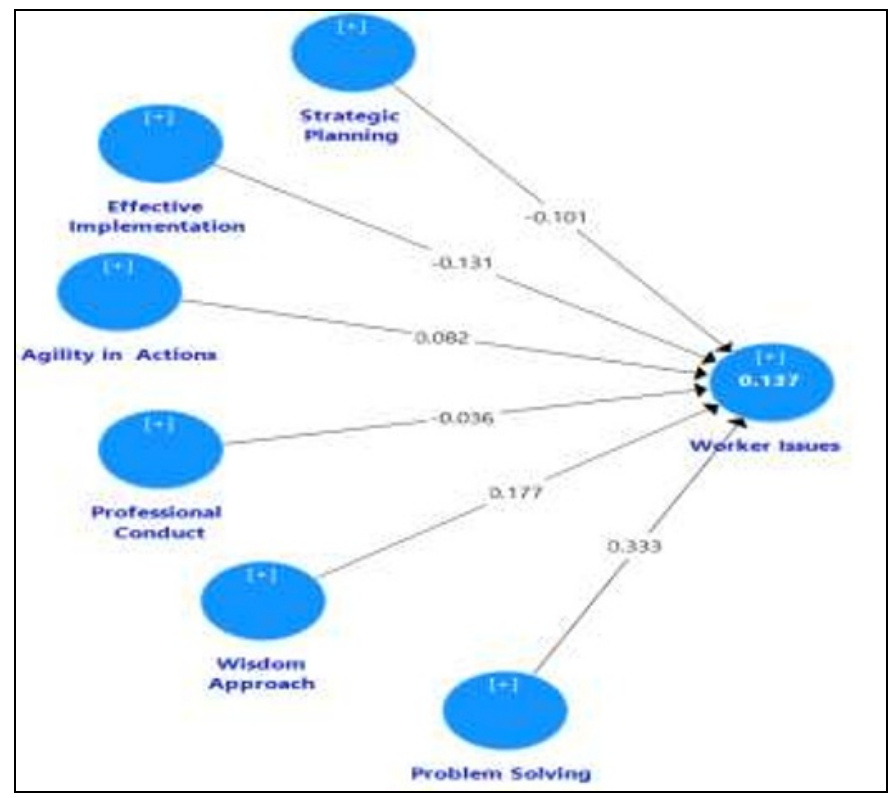

Fig. 3. Results of Structural Model of the Study.

The path co-efficient ( $\beta$ values) of each path in figure 3 are summarized as in table 3 .

Table 3. Impact of Leadership Qualities on Workers Issues.

\begin{tabular}{|c|c|c|c|}
\hline Rank & Independent Variables & $\begin{array}{c}\text { Path Co-efficient } \\
\quad(\beta \text { value) }\end{array}$ & $\begin{array}{c}\text { Dependent } \\
\text { Variable }\end{array}$ \\
\hline 1 & Problem Solving & 0.333 & \multirow{6}{*}{ Worker Issues } \\
\hline 2 & Wisdom Approach & 0.177 & \\
\hline 3 & Effective Implementation & -0.131 & \\
\hline 4 & Strategic Planning & -0.101 & \\
\hline 5 & Agility in Actions & 0.082 & \\
\hline 6 & Professional Conduct & -0.036 & \\
\hline
\end{tabular}

Table 3 demonstrates the ranks of leadership qualities groups in terms of $(\beta)$ their impacts towards workers issues. It perceived that Problem Solving group of qualities is the most dominant in handling workers issues with co-efficient value of 0.333 followed by Wisdom Approach group with co-efficient value of 0.177 . However Professional Conduct group of qualities is having the smallest co-efficient value of -0.036 which indicates that this group is giving the least impact in handling workers' issues. Thus, it can be concluded that problem solving group of qualities has the strongest impact toward workers' issues. 


\subsection{Overall assessment}

Goodness of Fit (GoF) defined as the geometric mean of both average variance extracted (AVE) and the average of $\mathrm{R}^{2}$ of all endogenous variables [24]. PLS results can be assessed globally for the overall model and locally for the measurement model and the structural model [25]. The model's overall goodness of fit should be the starting point of model assessment if the model does not fit the data; the data contain more information than the model conveys [25]. The criteria of GoF to determine whether GoF values are no fit, small, medium, or large to be consider as global valid PLS model are given by Akter et al. [24] as presented as table 4 .

Table 4. GoF Index Criteria.

\begin{tabular}{|l|c|}
\hline \multicolumn{1}{|c|}{ GoF Value } & GoF Criteria \\
\hline GoF less than 0.1 & No fit \\
\hline GoF between 0.1 to 0.25 & Small \\
\hline GoF between 0.25 to 0.36 & Medium \\
\hline GoF greater than 0.36 & Large \\
\hline
\end{tabular}

The calculation formula of GoF was adopted from Akter et al. [24] as follow:

$$
G o F=\sqrt{\overline{A V} \bar{E} X \bar{R}^{2}}
$$

Where, $\mathrm{R}^{2}$ for this study is 0.137 and the Average of AVE for endogenous variables (6 groups of leadership qualities) is 0.639

Thus,

$$
\begin{aligned}
& G o F=\sqrt{0.639 \times 0.137} \\
& G o F=0.30
\end{aligned}
$$

Therefore, the GoF value for this study is 0.30 , which in the range of 0.25 to 0.36 cutoff value as indicated in table 4. This certifies that the developed model is medium in explaining the issues of construction workers for Makkah's construction industry.

\section{Conclusion}

The developed PLS-SEM path model of structural relationship between leadership qualities and worker issues for Makkah's construction industry comprised of 56 leadership qualities which are clustered into 6 groups and one dependent variable consisted of 21 worker issues. Assessments on the model were carried out and found that after carrying out 12 iterations all the manifests in the measurement model are reliable and valid. In the structural model, it was found that Problem Solving group of qualities is the most dominant in handling workers issues with co-efficient value of 0.333 . Finally, overall assessment on the model shows that the model is fit with Goodness of Fit (GoF) value of 0.30 . This relationship 
model can assist the Saudi's construction stakeholders in nominating potential leaders to handle workers issues effectively and efficiently.

The authors would like to thank and acknowledge Universiti Tun Hussein Onn Malaysia (UTHM) for the financial support using the grant name "Contract Grant A074 Renalcare Research Fund". Also, the authors would like to thank and appreciate the construction experts for their significant contributions to this research.

\section{References}

1. G. H. Jarad. The construction manager leading characteristics for the success of construction projects in the Gaza Strip. The Islamic university of Gaza: M.Sc. Thesis, (2012)

2. A. A. Tabassi, M. Argyropoulou, K. M. Roufechaei \& R. Argyropoulou. Leadership Behavior of Project Managers in Sustainable Construction Projects. Procedia Computer Science, 100, 724-730, (2016)

3. G. Ofori, S. U. R. Toor. Leadership and Construction Industry Development in Developing Countries. Journal of Construction in Developing Countries, 17 (2012)

4. Saudi Arabia Infrastructure Report Q1 2017: Retrieved on January 2018 from http://www.prnewswire.com/news-releases/saudi-arabia-infrastructure-report-q12017-300380631.html

5. N. Alotaibi, M. Sutrisna, \& H. Chong. Managing Critical Factors Causing Delays In Public Construction Projects In Kingdom Of Saudi Arabia. Curtin University: Ph.D Thesis, (2014)

6. G. S. A. Elawi, M. Algahtany \& D. Kashiwagi. Owners' Perspective of Factors Contributing to Project Delay: Case Studies of Road and Bridge Projects in Saudi Arabia. Procedia Engineering, 145, 1402-1409, (2016)

7. F. A. Gul, \& A. M. Ali. Saudi Crane Collapse Masjid al-Haram (Lack of Safety). IJRDO-Journal of Social Science and Humanities Research, 8 (1), (2016)

8. N. Al-Emad, and I. A. Rahman. An initial investigation on the challenges of managing construction workforce in Saudi Arabia. IOP Conference Series: Materials Science and Engineering. Vol. 271. No. 1. IOP Publishing, (2017)

9. R. Almannaee. Migrant workers in the construction industry in United Arab Emirates (UAE): The role of the Ministries of Labour and Foreign Affairs in enforcing fair payments and minimum wages M.Sc. Thesis (The Hague: Int. Institute of Social Studies) pp 11-64, (2014)

10. J. B. Andrieu, A. Ucla, M. Lee. Addressing workers' rights in the engineering and construction sector - Opportunities for collaboration BSR Working Paper (San Francisco: Humanity United) pp 12-38, (2016)

11. G. Ofori. Leadership for future construction industry: Agenda for authentic leadership. International Journal of Project Management, 26 (6), 620-630, (2008)

12. B. Benator, A. Thumann. Project Management \&Leadership Skills for Engineering \& Construction Projects, CRC Press.Unites States, (2003)

13. N. A. N. Nasaruddin, I. A. Rahman. Exploratory Study on Malaysia Construction Leadership. In MATEC Web of Conferences (Vol. 103, p. 03005). EDP Sciences (2017) 
14. I. A. Rahman, N. Al-Emad, \& S. Nagapan. Projects delay factors of Saudi Arabia construction industry using PLS-SEM path modelling approach. In MATEC Web of Conferences (Vol. 81, p. 07001). EDP Sciences, (2016)

15. N. Al-Emad. Structural relationships model of delay factors in Makkah construction industry (Master dissertation, Universiti Tun Hussein Onn Malaysia, (2016)

16. B. Nikmehr, M. R. Hosseini, R. Rameezdeen, N. Chileshe, P. Ghoddousi \& M. Arashpour. An integrated model for factors affecting construction and demolition waste management in Iran. Engineering, Construction and Architectural Management, 24(6), 1246-1268, (2017)

17. J. Hulland. Use of partial least squares (PLS) in strategic management research: A review of four recent studies. Strategic management journal, Vol. 20, No. 2, pp. 195204, (1999)

18. A. A. Aibinu, F. Y. Y. Ling \& G. Ofori. Structural equation modelling of organizational justice and cooperative behaviour in the construction project claims process: contractors' perspectives. Construction Management and Economics, 29(5), 463-481, (2011)

19. I. A. Rahman \& S. Nagapan. Causative factors of Construction waste generation in Malaysia. Universiti Tun Hussein Onn: Penerbit UTHM, (2015)

20. C. Fornell \& D. F. Larcker. Evaluating structural equation models with unobservable variables and measurement error. Journal of marketing research, 39-50, (1981)

21. J. F. Hair, G. T. M. Hult, C. M. Ringle \& M. Sarstedt. A Primer on Partial Least Squares Structural Equation Modeling (PlS-SEM). United State of America: SAGE Publications, (2017)

22. A. A. Aibinu \& A. M. Al-Lawati. Using PLS-SEM technique to model construction organizations' willingness to participate in e-bidding. Automation in construction, 19(6), 714-724, (2010)

23. J. Cohen. Statistical Power Analysis for the Behavioral Sciences. 2nd ed. New Jersey: Lawrence Erlbaum Associates Publishers (1988)

24. S. Akter J. D'Ambra \& P. Ray. An evaluation of PLS based complex models: the roles of power analysis, predictive relevance and GoF index. Proceedings of the 17th Americas Conference on Information Systems (AMCIS2011) (pp. 1-7). Detroit, USA: Association for Information Systems, (2011)

25. J. Henseler. Partial least squares path modeling. In Advanced methods for modeling markets (pp. 361-381). Springer, Cham, (2017) 